\title{
Visualizaciones de la experiencia estética: De vuelta de Italia (1888), de Benito Pérez Galdós
}

\author{
Visualizations of the Aesthetic Experience: De vuelta de Italia \\ (1888), by Benito Pérez Galdós
}

\author{
doi) doi.org/10.48162/rev.54.002 \\ Nadia Arias \\ Facultad de Filosofía y Letras, Universidad Católica Argentina \\ nadia_arias@uca.edu.ar
}

\section{Resumen}

Tomando como punto de partida la faceta pluridisciplinar y plástica de Benito Pérez Galdós (1843-1920), en el presente trabajo nos proponemos abordar la importancia de la configuración visual en sus relatos de viajes, recorridos estético-culturales por el viejo continente. En particular, analizaremos algunos de los procedimientos empleados en De vuelta de Italia que contribuyen a otorgar densidad descriptiva y visual al relato, a la vez que constataremos los desafíos que este tipo discursivo supone para el escritor canario.

Palabras clave: Benito Pérez Galdós; relato de viajes; discurso visual.

\begin{abstract}
Framed in the multidisciplinary and plastic facet of Benito Pérez Galdós (1843-1920), the aim of this paper is to study the importance of visual composition in his books of travel, aesthetic-cultural tours around the old continent. In particular, we will analyze some of the procedures used in De vuelta de Italia that contribute to the story's descriptive and visual density.
\end{abstract}


Also, we will verify the challenges that this discursive type poses to the Canarian writer.

Keywords: Benito Pérez Galdós; travel report; visual discourse.

Inscriptos en un nuevo giro, aquel que W. J. Thomas Mitchell, en el ámbito anglosajón, denominó "pictorial" (2014) y G. Boehm, en el germánico, “icónico” (2011), la imagen acontece como un nuevo paradigma epistemológico que atraviesa diametralmente una amplia variedad de campos de investigación. No se trata, simplemente, de una proliferación de imágenes en las últimas décadas, sino de una transformación en el estudio de la cultura, que desplaza el centro de su ontología desde el logos a la imagen.

En el marco de los Estudios Visuales, Mitchell (2014) concibe una teoría de la visualidad que aborda la percepción no solo desde un punto de vista fisiológico, sino en su dimensión cultural, como construcción visual. En otros términos, el foco está puesto en la producción de significado cultural a través de la visualidad, entendida como mediadora de las relaciones sociales. Implica, en consecuencia, "un descubrimiento postlingüístico y postsemiótico de la imagen, una compleja interacción entre la visualidad, las instituciones, el discurso, el cuerpo y la figuralidad" que pone de relieve las relaciones entre "un sujeto que mira" y un "objeto mirado" (Guasch, 2003: 10).

Los estudios galdosianos no se encuentran ajenos a estas nuevas perspectivas críticas. Ya en 1992, en el contexto del V Congreso Internacional Galdosiano celebrado en Las Palmas de Gran Canaria, la exposición "La ilustración gráfica en el universo galdosiano", a cargo de Sebastián Hernández Gutiérrez y José Pérez Vidal, puso de relieve la inclinación del escritor canario por el coleccionismo de recuerdos gráficos: 
postales de viajes, mapas, folletos e ilustraciones de algunas de las primeras ediciones de sus obras dan cuenta de la centralidad de la interacción imagen-texto en su producción literaria.

Por su parte, Stephen Miller (1999/2001/2009) configuró las bases de una línea de investigación centrada en el análisis de la visualidad en la obra galdosiana y en el estudio de las metarelaciones entre palabra e imagen en el escritor canario. Sus trabajos no solo dieron cuenta de la faceta plástica desplegada en los álbumes de grabados que pintó entre los años sesenta y setenta, sino que también llamaron la atención sobre la necesidad de que se recogieran y se catalogaran todos los dibujos confeccionados por el autor al margen de muchos de los manuscritos de sus novelas. En una entrevista con José María Carretero en 1914, Galdós reconoció, en efecto, tener dibujados a lápiz todos los personajes que, luego, formarían parte de su mundo ficcional, pues "antes de crear literariamente los personajes de mis obras -afirma- los dibujo con el lápiz, para tenerlos después delante mientras hablo de ellos" (Bly, 1992: 284).

Esta faceta plástica del pluridisciplinario escritor, que se constata también en variadas críticas y reseñas de arte, se traslada a la materia poética en un relato particularmente atento a la visualidad. Recurriendo a la descripción como técnica estructural, aquella deviene en factor tanto recurrente como relevante de la construcción del relato: desde las continuas evocaciones al arte pictórico hasta la conformación de retratos kinésico-corporales que evocan claras imágenes mentales en los lectores, la narración se carga de procedimientos que potencian la dimensión visual y que amplían el espectro semántico de un texto esencialmente 
multimodal, en el que la transmisión de significados se entiende como un proceso interactivo y dinámico, realizado a través de diversos códigos de sentido (Kress/ Van Leewen, 2001; Moya Guijarro/ Pinar Sanz, 2007).

En este contexto de transdisciplinariedad del quehacer poético y de configuración visual de la narración, se enmarcan los relatos de viajes galdosianos, publicaciones en prensa en formato epistolar que comprenden auténticos itinerarios estético-culturales por el viejo continente. Discursos de naturaleza bifronte que manifiestan fines informativos pero sometidos a claros procesos de "literaturización", estos relatos codifican auténticos "espectáculos imaginarios" (Carrizo Rueda, 1997: 14) en los que el itinerario actúa como verdadero protagonista. Como indica la Dra. Carrizo Rueda, cuyos lineamientos teóricos seguimos, los libros de viaje dan cuenta de fragmentos de mundo que configuran "espectáculos para la contemplación" (1997: 14), destinados a "diseñar la imagen de las sociedades visitadas [...], crear espacios dentro del discurso destinados a la admiración [...] y presentar materiales que sirvan para enriquecer tareas de conocimiento" (1997: 12).

En el presente trabajo, nos proponemos analizar la importancia que adquiere la configuración visual en De vuelta de Italia y algunos de los procedimientos empleados en su consecución. Escrito en Santander pocos días después de concluida la travesía, el relato seleccionado describe el recorrido efectuado en 1888 en tren por una serie de ciudades itálicas -Roma, Venecia, Florencia, Verona, Bolonia, Padua, Nápoles y Pompeya-junto a su frecuente compañero de viaje, 
José Alcalá Galiano ${ }^{1}$. Fue publicado, con periodicidad quincenal, a fines de noviembre del mismo año inicialmente bajo la forma de cartas, enviadas por entregas al periódico bonaerense La Prensa; recién en 1928, serán recogidas en el noveno volumen de las Obras inéditas, ordenadas y prologadas por Alberto Ghiraldo (Galdós, 1928).

La riqueza plástica de Italia, cuna y epicentro del arte occidental, le proporciona una materia perfecta para el despliegue de sus dotes visuales en unas cartas que "contendrán apreciaciones artísticas e históricas enlazadas con los nuevos aspectos que ofrece la moderna Italia, transformada por la unidad" (Galdós, 2011: 69), al tiempo que lo enfrentan al desafío de describir ciudades, cuya imagen visual forma parte del acervo popular: "Italia es conocida aun por los que no la han visitado, y las representaciones gráficas y descriptivas de sus monumentos son, digámoslo así, del dominio público. ¿Quién no conoce las lagunas de Venecia, la logia de Florencia y la plaza de San Pedro?" (2011: 69).

En el cruce entre la exuberancia plástica del escenario de viaje y la pretensión de originalidad descriptiva se asienta la particular visualidad de este relato de viajes.

\footnotetext{
${ }^{1}$ La única mención que Galdós hace de él en su relato se ubica en el apartado correspondiente a "Verona", ciudad en la que, con motivo de la visita a la tumba de la Julieta shakespeariana, refiere la presencia de su "compañero de viaje" (2011: 99). Por fuentes extratextuales y por las propias alusiones que Galdós hace de este viaje en Memorias de un desmemoriado, se tiene la certeza de la identidad de su acompañante.
} 


\section{La visualidad evidente: la descripción y sus recursos de concreción visual}

Partiendo del anclaje teórico propuesto por la Dra. Carrizo Rueda (1995/1997/2008), el relato de viajes constituye un "discurso narrativo-descriptivo en el que predomina la función descriptiva como consecuencia del objeto final, que es la presentación del relato como un espectáculo imaginario, más importante que su desarrollo y su desenlace" (1997: 28). Sostén del discurso, la descripción absorbe la función narrativa, de modo que "Ios episodios se suceden como en una especie de friso, donde cada uno de ellos reviste interés por sí mismo" y no en virtud de la consecución de una resolución final (Carrizo Rueda, 2008: 19).

En efecto, las descripciones ocupan un lugar central en la codificación del relato de viajes galdosiano y en la construcción de su discurso visual: retienen la atención del receptor, al mismo tiempo que "actúan como adjetivos que van revelando todo lo relativo a una 'imagen de mundo' que el discurso asume como escritura de cierto espacio recorrido" (Carrizo Rueda, 2008: 20).

Entre los principales procedimientos descriptivos utilizados por Galdós en De vuelta de Italia para dotar al relato de densidad visual, destacamos los siguientes:

\section{1. Comparaciones}

Una de las estrategias más frecuentes consiste en establecer analogías entre las ciudades itálicas visitadas y otras españolas. Para ello, parte de la base del reconocimiento de las estrechas semejanzas que unen a ambas naciones. En el siguiente 
fragmento se observa una forma de comparación consistente en la identificación de unas ciudades (las visitadas) con otras (las españolas):

Hallamos paridad tan grande entre las ciudades del Mediodía de Italia y las nuestras, que a ratos la ilusión parece completa. Las casas parecen las mismas, el campo y los árboles idénticos, la gente idéntica también en el vestir, y más aún en la viveza de la imaginación y en la rapidez un tanto alborotada del lenguaje (2011: 67).

El símil con la nación española le brinda al autor oportunidad de establecer un punto de referencia concreto para que el receptor se forme una imagen clara de lo descripto sin que medie la experiencia directa: el anfiteatro romano de Verona es "mayor que la mayor de nuestras plazas de toros" (2011: 100), las islas de Ischia, Prócida y Capri solo pueden compararse en belleza con las Cies, en la entrada del puerto de Vigo, aunque estas carecen de la vegetación y arqueología de las italianas (2011: 146).

De igual modo que con frecuencia detiene su relato para aclarar conceptos que puedan resultar oscuros ${ }^{2}$, el viajero se vale de estas comparaciones con el fin de aproximar lo observado a la comprensión del lector.

Mediante analogías hechas, en otros casos, entre las propias ciudades italianas visitadas, Galdós habilita la construcción de un sistema de redes de vinculación visual entre los espacios recorridos. De la arquitectura de los edificios pompeyanos, por

\footnotetext{
${ }^{2}$ Así, por ejemplo, ante la obra de Miguel Ángel, explica que "Ilaman los italianos 'Pietá' al grupo de la Virgen María con Cristo muerto, que nosotros llamamos la Soledad o las Angustias" (2011: 82).
} 
ejemplo, aclara que "no es monumental, ni puede compararse a las de los palacios, templos, termas y basílicas de Roma" (2011: 159), al igual que precisa que Padua "no encierra monumentos grandiosos como Venecia" (2011: 128). Asimismo, de Verona indica que "la ciudad es original, aunque no tanto como Venecia; artística, aunque bastante menos que Florencia. Posee antigüedades romanas, aunque no tan hermosas como las de Roma" (2011: 89). La propia configuración visual de una ciudad deviene, por tanto, en parámetro para las siguientes que integran el itinerario.

Por otra parte, Galdós incluye comparaciones muy plásticas con la intención de aclarar o especificar un elemento descripto:

A una distancia que no se puede apreciar bien, porque el terror lo impide, se ve la horrible cavidad por donde sale el resuello abrasado del volcán con cadencia isócrona que se asemeja a la respiración de un gigante. Entre el vapor blanco y espeso salen, esputados con formidable fuerza, pedazos de lava ardiente, roja como el hierro en la fragua [...]. Salimos a terreno seguro con la impresión de haber estado momentáneamente fuera del planeta, o en el mismo infierno, despertando como de un sueño, y sintiéndonos felices por el regreso a nuestro mundo habitual (2011: 154, mi subrayado).

Nótese en las comparaciones empleadas para describir el Vesubio pompeyano la naturaleza bifronte de los términos de comparación usados: en algunos casos, se utilizan referentes visuales muy concretos ("roja como el hierro en la fragua"), mientras que, en otros, el Galdós novelista le cede al viajero símiles más ambiguos y que apelan al horizonte cultural de su lector, como en el siguiente pasaje: "el resuello abrasado del 
volcán con cadencia isócrona que se asemeja a la respiración de un gigante".

\section{2. Intertextos culturales}

En otros casos, son intertextos culturales aquellos que se emplean como estrategia para acortar la distancia imaginativoafectiva entre los receptores y el texto, y potenciar el referente visual.

Así, la complicación del plano veneciano y la dificultad de su recorrido son asociados con el mítico dédalo, de modo tal que "se necesita un trozo bastante grande del hilo de Ariadna para andar sin perderse" (2011: 110). Siguiendo la tradicional imagen de Venecia como laberinto, las calles estrechas y los callejones abiertos entre las medianerías de las casas circunscriben en el espacio más pequeño posible el enredo más complejo de senderos, que genera un estado de desorientación en todo aquel que intenta recorrerlo.

Nápoles, por su parte, es descripta a partir de tópicos bucólicos, cual Arcadia moderna que parece vivir en una nueva edad de oro de abundancia, inocencia y felicidad, en donde reina la paz y la armonía con la naturaleza. La ciudad se presenta como ambiente idílico, diametralmente opuesto a la industriosa Manchester, en el que el hombre goza de la bondad del clima y vive en comunión con su entorno.

Igualmente, la caravana turística que se congrega en torno a la tumba de la enamorada shakespeariana en Verona se asocia a las peregrinaciones medievales: los visitantes la recorren "con verdadero recogimiento, hasta parece que rezan entre dientes y que elevan su pensamiento a la región ideal de aquel amor tan puro y acendrado" (2011: 99), de modo tal que este 
"santuario del amor juvenil" solo puede compararse "a las [peregrinaciones] que acuden a ciertos lugares de devoción católica, habitados por imágenes milagrosas que conceden salud a los enfermos" (2011: 97).

\section{3. Imágenes sensoriales}

Si bien la ciudad es el escenario central sobre el que se detiene la mirada del viajero, el escritor canario nos ofrece, asimismo, descripciones sobre la naturaleza que acompaña los entornos urbanos. Se trata de referencias geográficas en las que esta actúa como marco de su emplazamiento. Mediante el uso reiterado de imágenes sensoriales, se ofrece una pintura absolutamente plástica y visual del espacio, como en el siguiente fragmento descriptivo dedicado al paisaje veronés $y$ el río Adige:

El Adige es impetuoso, revuelto, de corriente fugaz $y$ bulliciosa por la arrancada que trae de los grandes declives de la cordillera próxima. Baja del Tyrol, pasa por Verona ya con caudal nutrido, y describiendo una enorme ese amenaza los muros y las calles de la ciudad como si quisiera llevárselos. Sus márgenes son agrestes, accidentadas, algo melancólicas; el paisaje oscuro y ceñudo con muchos cipreses, algunos de gigantesca talla. La comarca de Verona es pintoresca y bien cultivada. A poco de extenderse por ella se ven las grandes planicies que mueren en el Adriático y que anuncian las playas aplaceradas de las lagunas. (2011: 96)

A través de enumeraciones, imágenes sensoriales y personificaciones, la descripción le otorga dimensión corporal al texto, convierte la imagen del entorno natural en palpable y perceptible. A la vez, el viajero oscila entre la admiración que 
la inmensidad del paisaje le despierta y la conmoción ante una naturaleza que se vislumbra como un imponente rival capaz de ejercer su poderío sobre la urbe.

Como si recordara sus primeros años de guía turístico en El Prado, Galdós también se vale de las imágenes sensoriales para la descripción del legado artístico de cada ciudad, elemento infaltable en este viaje estético-cultural. La mirada culta del viajero, interesado desde niño por el dibujo y las acuarelas, se detiene en la sólida y minuciosa observación de un corpus seleccionado de pinturas, esculturas y obras arquitectónicas que definen la identidad de cada urbe:

San Marcos deslumbra por su traza oriental, por su decoración policroma, sus cúpulas y el lujo bizantino de sus mosaicos sobre fondo de oro. El palacio ducal, adaptación maravillosa del arte gótico al genio veneciano, ostenta su doble arcada ojival en que el mármol, labrado como una joya, parece competir con el marfil. (2011: 112)

Las imágenes sensoriales otorgan, también, al escritor canario la posibilidad de entrecruzar ambos planos, el propiamente topográfico y el estético, al evocar una imagen concreta del escenario retratado mediante su asociación con referentes pictóricos.

La naturaleza parece nutrirse del arte, es decir, ser una extensión de la paleta de los pintores que lo habitan, ya sea porque el arte imite a la naturaleza o porque sea esta la que quiera parecerse a aquel. Los paisajes lacustres venecianos son descriptos cual si fueran un cuadro, pues "todo allí es colorido, armonía de masas y líneas" (2011: 109), al mismo tiempo que "producen un 'partido' admirable para la pintura" (2011: 108) y sirven de atractivo modelo a los artistas que trabajan con los 
caballetes en sus márgenes. Si la campiña toscana "es el paisaje triste y minucioso que sirve de fondo a los cuadros de todos los pintores florentinos del siglo XV" (2011: 127), el mar que se extiende a orillas de Nápoles compite con el arte y "supera en diafanidad y hermosura a los más chillones matices que admiramos en las bandejas", de modo que "la Naturaleza parece querer mostrarse y declararse artista" (2011: 146).

En suma, queda constatado cómo Galdós se vale de la función predominantemente descriptiva propia del relato de viajes para dotar al suyo de un alto grado de densidad visual y hacer del propio discurso una "imagen".

\section{La visualidad escondida: originalidad y aporte de la mirada galdosiana}

En un itinerario desprovisto de la originalidad de lo desconocido, conformado por esos sitios que "todo el mundo ha visto antes de estar en ellos" (2011: 155), Galdós apuesta por la primacía de la realidad y el peso de la observación directa:

Venecia, antes de ser vista, se nos figura que ha de aparecer a nuestros ojos desmejorada por la vulgarización excesiva de sus encantos. $Y$, sin embargo, no sucede así, por muchas noticias que se tengan de una ciudad y por mucho que se la haya visto pintada, ya en cuadros magníficos, ya en las tapas de las cajas de guantes, siempre la contemplación real de la misma nos hace rectificar ideas e imágenes. El natural da siempre tonos e inflexiones que nadie prevé. Hay en el color efectivo de las cosas algo que no es lo que se había imaginado, por bien imaginado que estuviese. De aquí que la curiosidad natural de nuestro ánimo y el ansia de nuestros 
ojos no se vean satisfechos sino ante la realidad (2011: 1067).

La novedad del relato galdosiano radica en el agregado de valor que aporta la observación directa: "Únicamente intentaré presentar algunos puntos de vista, resultado de la observación personal" (2011: 69). En esta línea, insiste en aclararle a su lector cuándo las descripciones provienen de la propia experiencia y cuándo de fuentes indirectas, así como también se encarga, en otros pasajes, de corregir, a partir de la contemplación del natural, ideas erróneas que la voz popular transmite sin sólido sustento.

A diferencia de las prácticas guías de viajes, "esos libros inapreciables que vemos en la mano de todo viajero" -definidas como "modelos de imparcialidad, de método y de rectitud", aspirantes a "dirigir los pasos del viajero, limitándose a indicarle los lugares y obras de arte que merecen visita, sin anticiparse a la admiración con entusiasmos hiperbólicos" (Galdós, 2011: 102)- el relato galdosiano no pretende participar de dicha escrupulosidad metódica ni recta objetividad. Por el contrario, parte de la observación, pero de una visión que está teñida tanto por la emoción que transmuta la percepción, como por la mirada de viajero culto, capaz de apreciar los cambios que la reciente unificación política italiana produjo en su larga tradición artística y cultural.

Si la observación directa otorga un plus de conocimiento, el desafío del relato de viajes galdosiano radica en cómo transmitir la visualización de esa experiencia, por definición intransferible: 
Parecíame que la veía por segunda vez, o que al menos no era cosa enteramente nueva para mí. Esto con respecto a la parte puramente arquitectónica de la ciudad desenterrada; pero en cuanto al espíritu que encierra, a las sombras que en ella moran, recuerdo o expresión misteriosa de la vida anterior, la visita a Pompeya fue para mí fuente de emociones enteramente desconocidas. (2011: 155)

Una forma de aproximarse a la visualización de esa experiencia consiste en develar la personalidad propia de cada lugar: Galdós procura, en palabras de Chantal Roussel-Zuazu, "evocar la poesía encerrada en cada región" (2005: 37).

De este modo, la descripción de Venecia, sin obviar los constituyentes propios del laudibus urbium latino ${ }^{3}$ (la historia de su República aristocrática y comerciante, su particular fisonomía y la de sus personajes prototípicos, los gondoleros, la tradicional costumbre que la convierte en foco de atracción para recién casados y pintores), trasciende el modelo retórico: Venecia es, para el escritor canario, la luna, "deslizándose sobre las aguas a la sombra de los palacios" (2011: 107), "la pureza y diafanidad del aire, casi siempre sin nubes" y "el azul intenso del cielo" (2011: 108); es "como un paréntesis, [...] una interrupción de las condiciones normales en que vive toda la humanidad civilizada" (2011: 107), en la que no hay gallos, caballos ni perros, pero abundan "las célebres palomas, huéspedes de aquellas cresterías admirables" (2011: 118). Venecia es la ciudad sin polvo, en la que los edificios, "al

\footnotetext{
${ }^{3}$ Según dicho modelo retórico, la descripción de una urbe supone, fundamentalmente, los siguientes puntos: "antigüedad y fundadores, situación y fortificaciones, fecundidad de los campos y provisión de agua, costumbres, edificios y monumentos y hombres famosos" (Carrizo Rueda, 1997: 85).
} 
envejecer, no toman el aspecto de ruina que en otras partes tienen" (2011: 109).

En su intento por dar cuenta de "lo visto, observado y sentido en Italia" (2011: 89) Galdós busca retratar la particularidad de cada urbe, el halo de misterio y poesía que hacen a su esencia más profunda, con el detalle y sensibilidad de aquel que se deja atravesar por el espacio que recorre.

Cada ciudad encierra un espíritu propio cuya percepción es absolutamente intransferible, así como cada obra artística posee un misterio que solo puede ser descifrado mediante la experiencia directa: las pinturas de la Capilla Sixtina pueden ser conocidas por todo hombre medianamente ilustrado, mas "solo pueden apreciarlas bien los que han penetrado alli" (2011: 77).

Los juicios estéticos, así como las valoraciones sobre los espacios recorridos, son inseparables de la experiencia vivencial y personal que surge del contacto directo. Así, el encuentro con el "Moisés" de Miguel Ángel es definido como una

de esas cosas que una vez vistas, no se pueden olvidar nunca. Entré en San Pedro Advíncula a la caída de la tarde. La iglesia estaba medio a obscuras, sin un alma. No se oía más ruido que el que hacía el sacristán con el manojo de llaves disponiéndose a cerrar la puerta. Acerquéme al brazo derecho del crucero, y al ver el Moisés, a la impresión que sentí se mezclaba el asombro, un terror inexplicable. (2011: 81)

Con unas pocas imágenes sensoriales, Galdós no nos describe simplemente el "Moisés", el objeto estético observado, sino la 
perspectiva bajo la cual este fue contemplado y la emoción irremediablemente personal que le despierta la percepción:

Parecíame que la severidad expresada en aquel mármol con rasgos tan enérgicos pertenecía a la vida real y que de aquellos labios fríos iban a brotar palabras de ira. Jamás el arte ha simulado los caracteres del espíritu y la expresión de la vida con mayor intensidad. Aquel mármol vive, aquella cabeza piensa, aquellas manos se van a mover, y aquel corpachón desmedido se va a erguir en su asiento (2011: 8081).

Llegados a este punto, lo visual se convierte solo en un modo parcial de transmitir las impresiones que emanan del contacto entre el sujeto y el espíritu de la ciudad, y aquel que usualmente encuentra en el discurso visual una forma privilegiada de comunicación se enfrenta a sus propios límites.

En un tipo de relato que carece de tensiones y expectativas sobre el desenlace, se genera, en consecuencia, otra forma de "situaciones de riesgo narrativo" (Carrizo Rueda, 1997: 25). Como postula Carrizo Rueda, en este tipo de discurso, "la densidad climática no depende de la dinámica interna del texto, sino que se trata de un salto a otro nivel que es el de las relaciones pragmáticas. Es en el contexto de los receptores donde determinadas situaciones producen expectativas capaces de generar un estado de inquietud" (1997: 42-3). Estos "picos de clímax" condensan, por consiguiente, expectativas sobre posibles desenlaces, "pero que se jugarán no en el discurso escrito sino en el funcionamiento de la sociedad a la cual está dirigido" (1997: 43).

En efecto, en aquellos pasajes del relato galdosiano en que se hace presente la isotopía de la observación directa y la 
experiencia y la de los consiguientes límites del discurso visual, aumenta la tensión y acontece una dosis de suspenso, enlazada con los interrogantes e intereses propios de los lectores modelos: receptores burgueses, cultos y viajeros, abiertos a los cambios políticos de una Europa finisecular marcada por la reciente unificación italiana, y atentos a los planteos estéticos y sociales de un Realismo signado por la primacía de la materialidad y el papel de la observación.

\section{Conclusiones}

Autodefinido como un aficionado a los viajes (Galdós, 2011: 101), "peregrino infatigable" (Galdós, 1968: 155), el autor de Fortunata y Jacinta encuentra en el relato de viajes un modelo narrativo e interpretativo idóneo para el despliegue de sus dotes visuales.

El itinerario por las ciudades itálicas y sus entornos naturales conforma el centro regulador del relato, que se hace explícito mediante la descripción y en el que el espectáculo de mundo y la vivencia del espacio recorrido devienen en factores prioritarios para la construcción de una determinada imagen.

En el despliegue de este friso, el poder del subtexto visual reconoce, empero, sus limitaciones. De vuelta de Italia nos interpela acerca del enigma que entraña el contacto directo e insustituiblemente personal con el espacio transitado durante el viaje. Al igual que en la contemplación de una obra de arte, la realidad observada, vivencia efímera en su temporalidad, permanece en la reconfiguración subjetiva que, desde la emoción, transmuta la percepción. 


\section{El viaje deviene, entonces, en auténtica experiencia estética, que traspasa el poder de la visualidad.}

\section{Bibliografía}

BLY, Peter, "El encanto de las artes visuales: relaciones interdisciplinarias en la novela galdosiana". En: Actas del V Congreso Internacional de Estudios Galdosianos. Las Palmas de Gran Canaria: Ed. Cabildo Insular, 1992. pp. 279-292.

BOEHM, G., “¿Más allá del lenguaje? Apuntes sobre la lógica de las imágenes". En: GARCÍA VARAS, A., Filosofía de la Imagen. Salamanca: Ediciones Universidad de Salamanca, 2011.

CARRIZO RUEDA, Sofía, "Un modelo formal de relato de viaje y el discurso de la alteridad en la Relatio del Obispo Liutprando". En: Stylos IV, 4 (1995): pp. 57-63.

CARRIZO RUEDA, Sofía, Poética del relato de viajes. Kassel: Reichenberger, 1997.

CARRIZO RUEDA, Sofía (ed.), Las escrituras del viaje. Buenos Aires: Biblos, 2008.

GUASCH, A., "Los estudios visuales. Un estado de la cuestión”. En: Estudios visuales no1 (2003): pp. 8-16.

HERNÁNDEZ GUTIÉRREZ, A. (comp.), “La ilustración gráfica en el universo galdosiano, Exposición (30 de agosto-30 de septiembre de 1993)". En: V Congreso galdosiano. Las Palmas de Gran Canaria, Universidad de Las Palmas de Gran Canaria, 1993.

KRESS, Gunther/ VAN LEEUWEN, Theo, Multimodal Discourse. The modes and media of contemporary communication. London: Arnold, 2001.

MILLER, Stephen, "Aspectos del texto gráfico de la edición 1881-1885 de los Episodios Nacionales". En: Actas del VII Congreso Internacional de Estudios Galdosianos. Las Palmas de Gran Canaria: Ed. Cabildo Insular, 1999. pp. 329-335.

MILLER, Stephen, "La caracterización gráfica del personaje galdosiano". En: VII Congreso Internacional Galdosiano. Las Palmas de Gran Canaria: Ed. Cabildo Insular, 2001. pp. 867-869.

MILLER, Stephen, Galdós gráfico 1861-1907: orígenes, técnicas y límites del sociomimetismo. Las Palmas de Gran Canaria: Cabildo de Gran Canaria, 2001.

MILLER, Stephen, Dibujos de Benito Pérez Galdós. Las Palmas de Gran Canaria: Cabildo de Gran Canaria, 2001.

MILLER, Stephen, “Los tres álbumes narrativos y la teoría literaria de Galdós: reflexión, recreación y creación artística". En: IX Congreso Internacional Galdosiano. Las Palmas de Gran Canaria, Universidad de las Palmas de Gran Canaria, 2009. pp. 419-423.

MITCHELL, W., “¿Qué quieren realmente las imágenes?", 2014. http://www.fadu.edu.uy/estetica-diseno-ii/files/2017/04/WJT-Mitchell_Que quieren_realmente_las_imagenescocompress.pdf, noviembre de 2019. 
MOYA GUIJARRO, Jesús/ PINAR SANZ, María Jesús, "La interacción texto/imagen en el cuento ilustrado. Un análisis multimodal”. En: Revista OCNOS n 3 (2007): pp. 21-38.

PÉREZ GALDÓS, Benito, Obras inéditas. Viajes y fantasías, ordenadas y prologadas por Alberto Ghiraldo. Madrid: Renacimiento, 1928.

PÉREZ GALDÓS, Benito, “Ciudades viejas: El Toboso". En: Anales galdosianos, año III (1968): pp. 155-161.

PÉREZ GALDÓS, Benito, La casa de Shakespeare. Portugal. De vuelta de Italia. Alicante: Biblioteca Virtual Miguel de Cervantes; Madrid: Biblioteca Nacional, 2011.

ROUSSEL-ZUAZU, C., La literatura de viaje en la literatura española del siglo XIX, una tipología (tesis doctoral). Universidad de Texas Tech: Estados Unidos, 2005.

Nadia Gisele Arias: Licenciada en Letras por la Universidad Católica Argentina y doctoranda en la misma institución. Es Profesora Adjunta de Teoría Literaria I y II y profesora invitada en el Seminario de Literatura Española de la Facultad de Filosofía y Letras de la Universidad Católica Argentina. Es Investigadora con Dedicación Especial y Coordinadora del Departamento de Letras en esa misma Universidad. Entre sus líneas de investigación se encuentran la narrativa española del XIX con foco en Pérez Galdós, el discurso kinésico, la Semiótica de la imagen y la Sociología de la edición e importación cultural 